\title{
BMJ Open Quantifying research output on poverty and non-communicable disease behavioural risk factors in low-income and lower middle-income countries: a bibliometric analysis
}

Luke Nelson Allen, ${ }^{1,2}$ Nicholas Fox, ${ }^{3}$ Alissa Ambrose ${ }^{4}$

To cite: Allen LN, Fox N, Ambrose A. Quantifying research output on poverty and non-communicable disease behavioural risk factors in low-income and lower middle-income countries: a bibliometric analysis. BMJ Open 2017;7:e014715. doi:10.1136/ bmjopen-2016-014715

- Prepublication history and additional material for this paper are available online. To view these files, please visit the journal online (http://dx.doi. org/10.1136/bmjopen-2016014715).

Received 12 October 2016 Revised 6 September 2017 Accepted 15 September 2017

\section{(a) CrossMark}

${ }^{1}$ WHO Global Coordination Mechanism on Non-

Communicable Diseases, World Health Organization, Geneva, Switzerland

${ }^{2}$ Nuffield Department of Primary Care Health Sciences, University of Oxford, Oxford, UK

${ }^{3}$ Department of Social Policy, London School of Economics and Political Science, London, UK

${ }^{4}$ Department of Undergraduate Medicine, University of Bristol, Bristol, UK

Correspondence to Dr Luke Nelson Allen; drlukeallen@gmail.com

\section{ABSTRACT}

Objectives Low-income and lower middle-income countries (LLMICs) bear a disproportionate burden of non-communicable diseases (NCDs). WHO has repeatedly called for more research on poverty and NCDs in these settings, but the current situation remains unquantified. We aimed to assess research output on poverty and NCD risk factors from these countries in relation to upper middle-income and highincome countries.

Design Bibliometric analysis of primary research published between 1 January 1990 and 4 May 2017. We searched 13 databases, combining terms for poverty and NCD behavioural risk factors (tobacco, alcohol, diet and physical activity). Independent dual review was used to screen titles, abstracts and full papers. Two-tailed t-testing and multiple linear regression analyses were used to compare differences in means.

Outcomes (1) Proportion of lead authors affiliated with institutions based in high and upper middleincome countries vs LLMICs. (2) Mean number of citations for publications from each region. (3) Mean journal impact factor for studies from each region. Results Ninety-one (67\%) of the 136 included studies were led by scientists affiliated with LLMICbased institutions. These authors represented 17/83 LLMICs (20\%), and their studies garnered 4.8 fewer citations per paper than studies led by high-income and upper middle-income-affiliated authors; however, this finding was non-significant $(P=0.67)$. Papers led by authors based in high-income and upper middleincome countries were published in journals with a mean impact factor 3.1 points higher than those from LLMICs (4.9 vs 1.7) adjusting for year of publication and number of citations $(P<0.001)$.

Conclusions Most poverty and NCD risk factor research is led by authors from a small number of LLMICs. These studies are being published in relatively low-impact journals, and the vast majority of LLMICs are not producing any research in this area that is vital to their social and economic development. The paucity of domestic evidence must be addressed to inform global policy.
Strengths and limitations of this study

- The WHO Global Action Plan and the WHO Prioritised Research Agenda both call for increased noncommunicable disease (NCD) research without quantitative justification; this is the first study to assess the quantity and quality of NCD and poverty research by World Bank region.

- We used a comprehensive search strategy, 13 major databases and independent dual review to maximise our chances of including all relevant papers.

- We focused our assessment on research that examines the association between poverty and NCD risk factors in developing countries; one of the most important aspects of the NCD epidemic from a policy standpoint.

- Research on other aspects of NCDs was not captured by our search.

- Impact factors and numbers of citations are imperfect proxies for quality.

\section{BACKGROUND}

Non-communicable diseases (NCDs)including cardiovascular diseases, diabetes, cancer and respiratory diseases-cause around two-thirds of global deaths, of which 16 million per year are premature (occurring before 70 years of age).$^{12}$ Over $80 \%$ of NCD mortality occurs in low-income and middle-income countries (LMICs), and individuals in these countries have a $50 \%$ higher risk of premature death compared with individuals living in high-income countries (HICs). ${ }^{13}$ NCDs have been described as the social justice issue of our generation and as one of the greatest development challenges of the 21st century. ${ }^{45}$

The bidirectional relationship between income and NCDs is fractal: these conditions incur international, national, household and individual financial costs through lost productivity, unemployment and long-term medical 


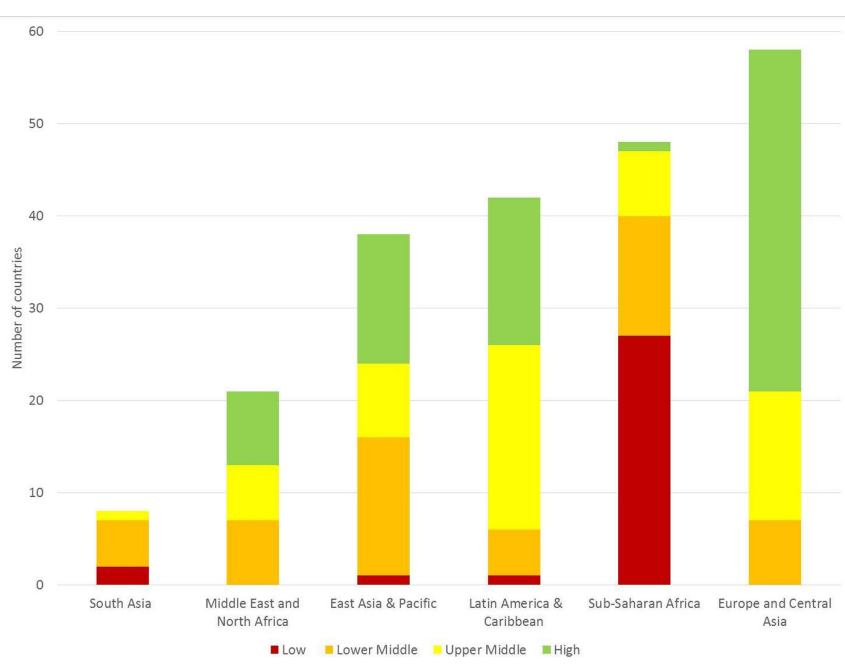

Figure 1 Income classification of countries in each World Bank geographical region.

expenses. ${ }^{6-12}$ The lost economic output in LMICs from 2011 to 2015 was estimated at US $\$ 7$ trillion. ${ }^{12}$

Poverty exposes individuals to the adverse political, economic and cultural conditions that cause NCDs and increases the risks of experiencing disability and premature death. ${ }^{13-22}$ Common factors include poor schooling, inadequate housing, hazardous workplaces and unplanned urbanisation. ${ }^{1}$ Behavioural risk factors such as tobacco and alcohol use, poor diet and physical inactivity are central in mediating socioeconomic NCD inequalities.

The story is not the same in every country, for instance, the correlation between physical activity and socioeconomic status is mediated by Gross National Income: obesity is a bigger problem for poorer groups in high-income countries but mainly affects affluent groups in low-income countries. ${ }^{22}$ In short, the factors that mediate the bidirectional relationship between poverty and NCDs are highly context-specific. High-income trends are not necessarily generalisable to the world's poorest countries, which often have higher relative and absolute burdens of NCDs.

Research on the relationship between poverty and NCD risk factors within developing countries is critical for the development of evidence-based, context-specific policy interventions; especially for addressing NCDs within the wider development agenda. The 2015 Sustainable Development Goals and the WHO Global Action Plan on NCDs both emphasise building national research capacity. ${ }^{23} 24$ These recommendations lack quantitative justification as we have little evidence about the current state of NCD research in the world's poorest countries. A previous bibliometric analysis of WHO 'Best Buy' implementation in LMICs showed wide variation between regions and the risk factors assessed, but no studies have specifically examined poverty and NCD risk factor research. ${ }^{25}$

We conducted a bibliometric analysis to fill this gap and assess likely impact of poverty and NCD risk factor research from low-income and lower middle-income countries (LLMICs) versus upper middle-income and high-income countries.

\section{METHODS}

Our primary objective was to quantify the proportion of poverty and NCD behavioural risk factor research in LLMICs that is led by LLMIC-affiliated researchers. The World Bank lists 83 LLMICs, with the vast majority of low-income countries concentrated in Sub-Saharan Africa (figure 1).

Secondary outcomes were estimates of research impact for publications from each World Bank income region derived from impact factor metrics and cumulative citations. We also extracted data on publication year, geographical region, study funder and which NCD risk factors were assessed.

We developed a search strategy that incorporated Medical Subject Headings terms and synonyms for NCDs, individual conditions, NCD risk factors, poverty, proxies for socioeconomic status and the 2015 World Bank list of LLMICs from the 2015 analytical classification. ${ }^{26}$

We ran the search (reproduced fully in online supplementary appendix 1) on Embase, Medline, Web of Science, Global Health and TRoPHI. We also searched grey literature in digital dissertations (Global full-text plus), WHOLIS (WHO Library) and the WHO regional databases: AIM (AFRO), LILACS (AMRO/PAHO), IMEMR (EMRO), IMSEAR (SEARO) and WPRIM (WPRO). We reviewed the first 100 hits from Google Scholar and searched Medline in-process and other non-indexed citations and the websites of the World Bank, Department for International Development, United States Agency for International Development and WHO, as well as scrutinising reference lists and contacting key authors to uncover additional or forthcoming work. We conducted the search in English but did not restrict results by language or age.

After duplicate removal, titles, abstracts and full-texts were independently screened by two reviewers with a random $10 \%$ sample screened by a third author. We included records written in English, Spanish, French, Portuguese, Italian and Sinhalese; published from 1 January 1990 to 4 May 2017; presenting primary data on one or more NCD behavioural risk factor stratified by one or more measures of poverty; with the study population based in one of the 83 World Bank-defined LLMICs.

From the included papers, we calculated the proportion of lead researchers (first authors) affiliated with institutions based in each World Bank region. Where an author was affiliated with two institutions, they were coded according to the higher-income country. We also recorded the number of times each article had been cited and the impact factor of the journal that the paper was published in, using Thompson Reuters data. This allowed us to derive a proxy measure for research impact. We used STATA (StataCorp) to perform two-tailed t-testing and 


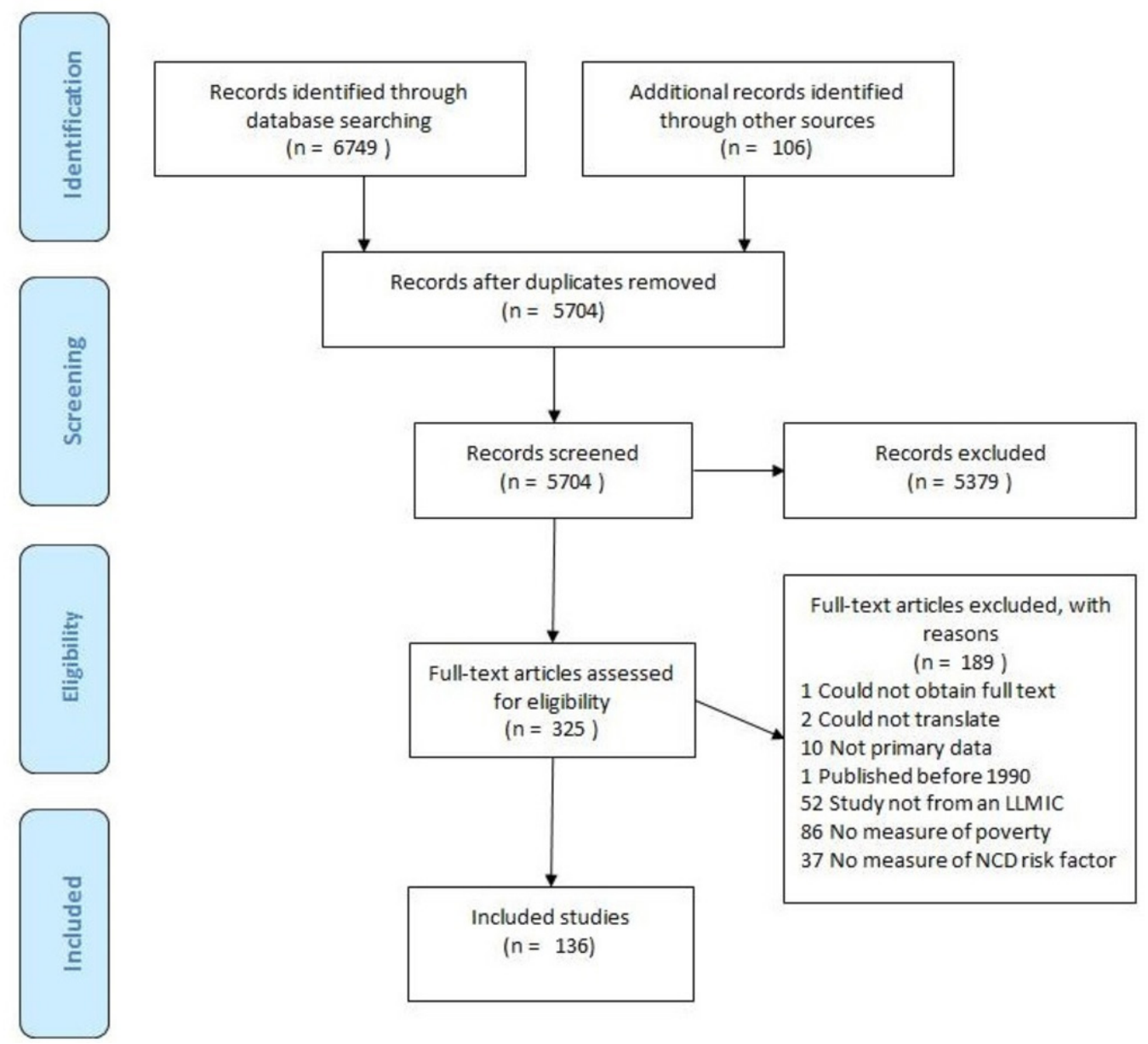

Figure 2 Preferred reporting items for systematic reviews and meta-analysis flow diagram. LLMIC, low-income and lower middle-income country; NCD, non-communicable disease.

linear regression analysis to determine whether differences in mean citations and mean journal impact factor were significant, using a threshold of $\mathrm{P}<0.05$. Ethical approval was not required.

\section{RESULTS}

At both stages of screening Cohen's $\kappa$ for inter-rater agreement was $>0.75$ (considered 'excellent agreement'). Our literature search returned 6749 records, and 106 additional records were retrieved from other sources. After screening, 136 papers met our inclusion criteria (see figure 2).

Four studies assessed populations based in more than one LLMIC. The remaining 132 showed a strong preponderance for South Asia, with almost half of the studies conducted in Indian populations (figure 3). Eighty-four of the 136 papers (62\%) were funded by LLMIC-based agencies.

Ninety-one $(67 \%)$ of the publications were led by authors affiliated with LLMIC-based institutions. These authors collectively represented 17 out of 83 World Bank-defined LLMICs; Benin, Ethiopia and Nepal were the only low-income countries represented by first authors. There were no papers from authors affiliated with institutions from $80 \%$ of all LLMICs.

Forty-five papers $(33 \%)$ were led by authors affiliated with high-income or upper middle-income countries. There was no clear trend over time in the proportion

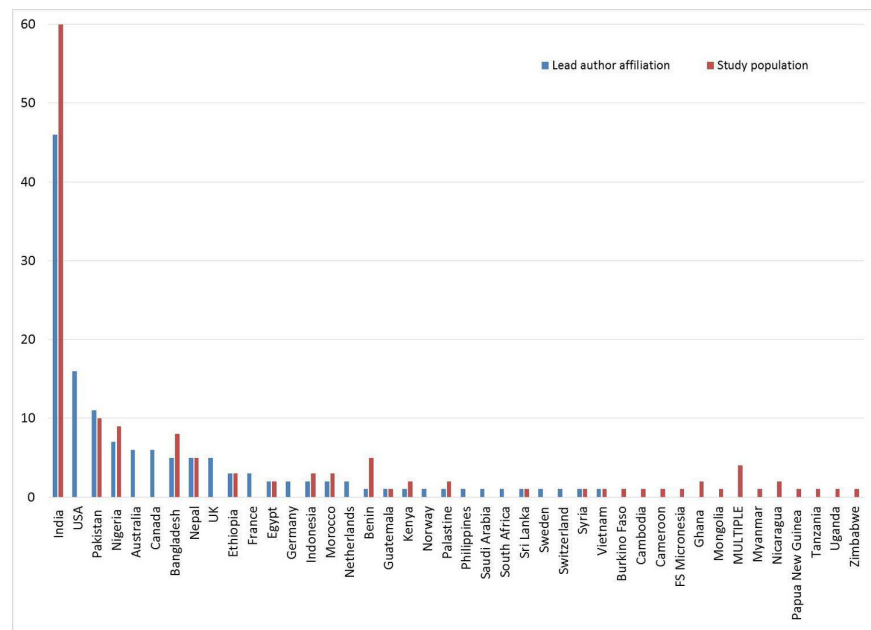

Figure 3 Location of lead authors institution and study population. 


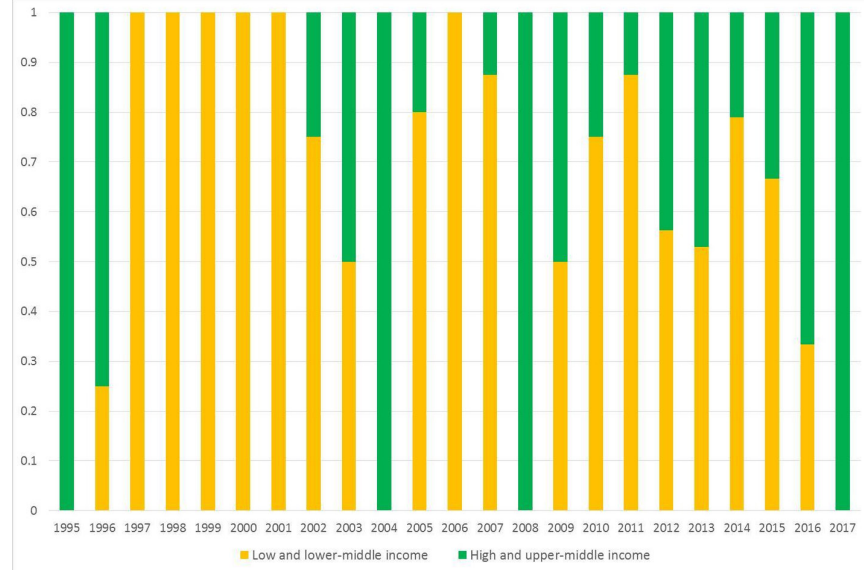

Figure 4 Proportion of studies led by authors affiliated with each income grouping from 1995 to 2017.

of papers led by higher versus lower income-affiliated authors (figure 4).

The number of papers published on poverty and NCD risk factors every year from 1995 to May 2017 has generally increased (figure 5). The most common study design is cross-sectional (table 1).

Table 2 shows that studies led by LLMIC-affiliated authors tended to had a much larger mean population size than those led by high-income/upper middle-income authors (380152 vs 17025 ).

The 45 papers led by authors affiliated with high-income/upper middle-income institutions were published in journals with a mean impact factor of 4.9 (figure 6). This was 3.2 points higher ( $95 \%$ CI 1.6 to 4.9 ) than papers led by LLMIC-affiliated researchers (mean impact factor 1.7). T-testing showed that the difference in means was significant at the 0.05 level $(\mathrm{P}<0.001)$.

Controlling for year of publication and number of citations, regression analysis showed that papers led by high-income and upper middle-income-affiliated authors

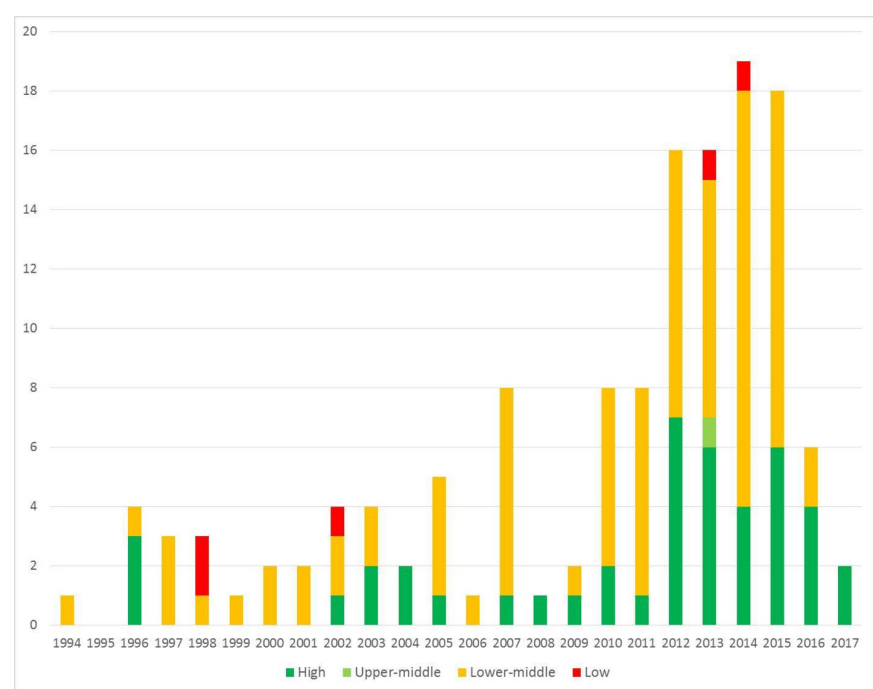

Figure 5 Total number of studies each year and first author's affiliation.
Table 1 Study designs

\begin{tabular}{lc}
\hline Study design & No of studies \\
\hline Cross-sectional & 102 \\
Case-control & 18 \\
Prospective cohort & 10 \\
Retrospective cohort & 4 \\
RCT & 1 \\
Before-after & 1 \\
\hline RCT, randomised controlled trial. &
\end{tabular}

were published in journals with an impact factor 3.1 points higher than those from LLMIC authors $(\mathrm{P}<0.001)$.

LLMIC-based authors garnered an average of 22.0 citations per paper; 4.8 fewer than the average paper from high-income and upper middle-income-affiliated authors; however, the difference between the means did not reach significance $(\mathrm{P}=0.67,95 \% \mathrm{CI}$ for difference in means -13.7 to 21.3$)$.

Most studies $(65 \%)$ assessed the association between poverty and a single risk factor; $21 \%$ assessed two risk factors; $8 \%$ examined three and $6 \%$ examined all four. As figure 7 demonstrates, tobacco was the most commonly assessed. Online supplementary file 1 provides study-level data on risk factors, country origins and paper metrics.

Papers assessing tobacco that were led by LLMIC authors were published in journals with a mean impact factor 4.6 times lower than those from high-income and upper middle-income-affiliated authors $(\mathrm{P}<0.001,95 \% \mathrm{CI}$ for difference in means 2.1 to 7.0). Differences in mean citations were non-significant at the 0.05 level.

\section{DISCUSSION}

This study is the first attempt to quantify research output on poverty and NCD risk factors in the countries that bear the greatest burden of NCD morbidity and mortality. ${ }^{3}$ Although LLMIC-affiliated scientists led $67 \%$ of the included papers, $80 \%$ of LLMICs have not produced any publications on poverty and NCD behavioural risk factors.

There were only two interventional studies, and the remainder were either cross-sectional, case-control or cohort studies. The same pattern in risk factor assessment was seen in every region with tobacco and diet being assessed more frequently than physical activity and alcohol use.

Papers led by authors based in high-income and upper middle-income countries were published in journals with a mean impact factor approximately three times higher than papers from LLMICs, after adjusting for citations and year of publication. We found a non-significant difference in mean citations for papers from higher versus lower income countries. Our findings do not provide evidence as to why LLMIC-based research has a lower impact, but we speculate that national research funding, the quality of health research training, institutional 
Table 2 Study characteristics

\begin{tabular}{|c|c|c|c|c|c|c|}
\hline $\begin{array}{l}\text { Lead author's institutional } \\
\text { affiliation }\end{array}$ & Low & Lower middle & Upper middle & High & $\begin{array}{l}\text { Low and } \\
\text { lower middle }\end{array}$ & $\begin{array}{l}\text { Upper middle and } \\
\text { high }\end{array}$ \\
\hline No of studies (\% total) & $5(4)$ & $86(63)$ & $1(1)$ & $44(32)$ & $91(66)$ & 45 (33) \\
\hline Mean publication year & 2005 & 2010 & 2013 & 2011 & 2009 & 2011 \\
\hline Mean population size & 627 & 403879 & 2983 & 173376 & 380152 & 17025 \\
\hline
\end{tabular}

capacity and softer factors such as the cultural values may play a role.

India was disproportionately over-represented in both terms of lead researchers and study populations. To test whether this was due to its large population size, we examined the number of publications per person for each country as well as other factors that might influence publication rate: spending on health, education and research and development, as well as physicians per capita. These are internationally comparable headline metrics routinely used for cross-country comparisons. They provide a rough indication of how well developed the academic life sciences community is likely to be, insofar as countries with very low spending on health, education and R\&D are unlikely to have, for example, an excess of Doctor of Philosophy students working on health research. Figure 8 shows that India's per capita publication rate is comparable with its close neighbours Pakistan and Bangladesh, but far below Nepal's publication rate. We note that this metric is less useful for countries with single studies and smaller populations. India's national expenditure on health, education and research

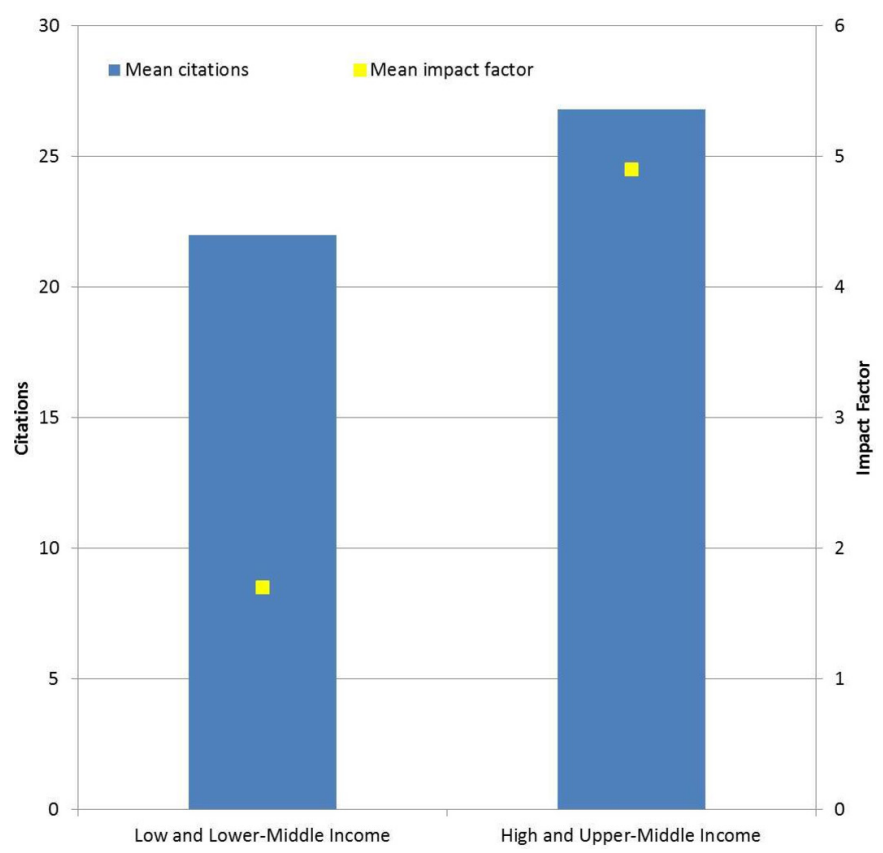

Figure 6 Lead author's location and paper metrics. and development is comparable with other countries at the same level of economic development, although slightly behind Asian peers such as Bangladesh, Vietnam and Sri Lanka. Both the Philippines and Indonesia have large populations but few publications; however, the four countries with the largest number of papers all have population sizes $>150$ million. With over 1.3 billion citizens, India's dominance seems to be partly explained by its large population size. Many academic institutions teach and publish in English which may play a role. Other contributing factors are harder to measure and compare across countries, such as India's relatively well-established research infrastructure and vibrant medical sciences community.

Conducting research in LLMICs can be extremely challenging. Political instability is a long-standing issue, along with unpredictable or non-existent research funding, weak academic institutions, underdeveloped collaborative relationships between partner organisations and language and cultural divides. The paucity of training, equipment and qualified personnel exacerbates these difficulties. ${ }^{27-29}$ Dakik argues that North-South collaboration can help to overcome many of these issues, as long as the approach is one of equal partnership. Targeting funds

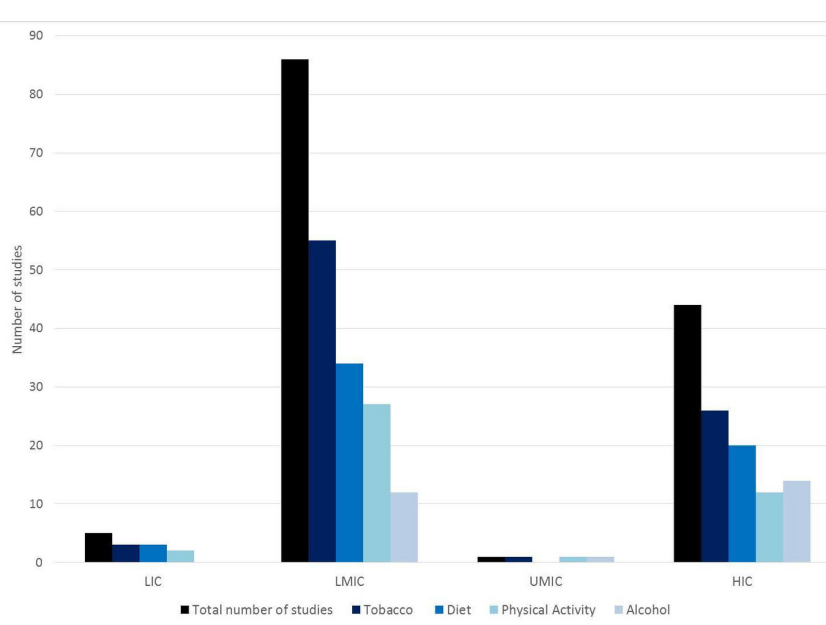

Figure 7 Total number of studies led by authors from each income group and risk factors assessed. HIC, high-income country; LIC, low-income country; LMIC, low-income and middle-income country; UMIC, upper middle-income country. 


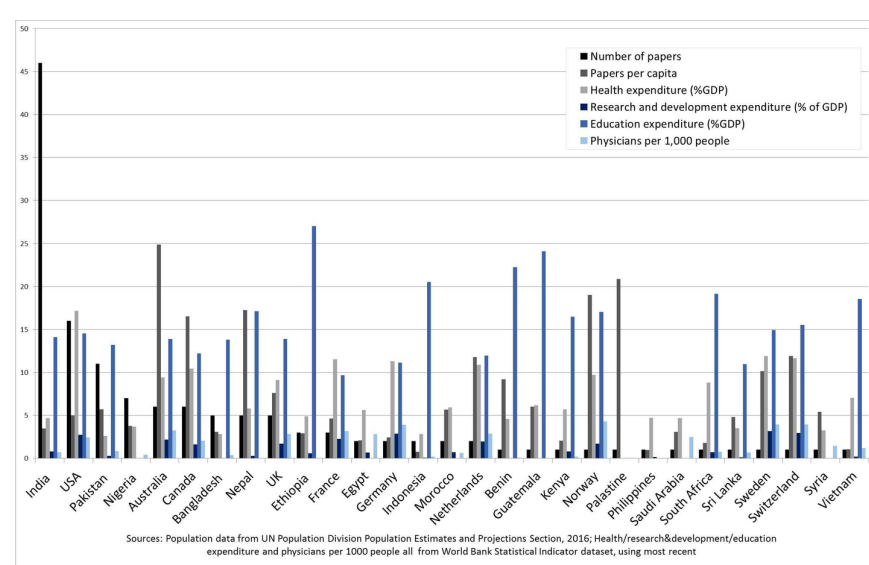

Figure 8 Number of studies from each country versus papers per person, physicians per 1000 people and national expenditure on health, education and research and development. GDP, gross domestic product.

to high-performing academics is another way of boosting impact and building research capacity in LLMICs. ${ }^{29-31}$

The main limitation of this study is our focus on poverty and behavioural risk factors as a proxy for NCD research. Low-income countries may be producing high-impact research in other areas that were excluded by our search, leading to a precise but inaccurate assessment of research output. A broader search would have delivered a more robust assessment of global NCD research. Unfortunately, we did not have the resources to handle such a large review and so focused on an area that features prominently in national and international NCD control strategies. Furthermore, research on poverty and NCDs has been highlighted as a priority area in the WHO Prioritised Research Agenda for NCDs and is central to the dominant development framing of the NCD epidemic. ${ }^{32}$ Our study is also limited by the assumption that the first author is the lead scientist. Strengths of the study include comprehensive search terms, the use of multiple databases, a focus on the most important aspect of NCD research from a policy perspective and independent dual review of papers.

A 2012 bibliometric review by Jones and Geneau ${ }^{25}$ showed that the relative proportion of LMIC authors leading research on 'priority interventions for NCDs' (WHO 'Best Buys') had increased since 2000. Our studyfocused on NCD risk factor and poverty research-found no such trend; however, we did find that tobacco is universally more studied than other risk factors, corroborating their work.

The relative paucity of LLMIC-based NCD research units is specifically addressed in the Global Action Plan on NCD Prevention and Control 2013-2020. ${ }^{33}$ Although two-thirds of poverty and NCD risk factor research has been led by LLMIC-based scientists, they collectively represent a minority of LLMICs. We emphasise the urgent need to strengthen incentives and capacity in these countries to undertake research on bidirectional links between NCDs and poverty in order to generate evidence to inform policies and programmes to address NCDs and poverty alleviation.

\section{CONCLUSION}

LLMICs bear disproportionately high burdens of poverty and NCDs, yet four-fifths of these countries have no research output on the four main NCD risk factors. This deficit is a barrier to the development of effective corrective policies. Building on our quantification of research capacity in LLMICs, future work should explore why research capacity is so low, and how it can be improved to support NCD prevention and control efforts in LLMICs.

Acknowledgements The authors wish to thank Shanthi Mendis who contributed to an earlier draft of the manuscript. We would also like to thank Nia Roberts, Kremlin Wickramasinghe, Julianne Williams and Nick Townsend for their help with the search strategy.

Contributors NF developed the original idea and drafted the early manuscript. LNA refined the methods, developed the search strategy and wrote subsequent versions of the manuscript. AA revised later versions of the manuscript and extracted and analysed data. All authors screened papers and extracted data.

Funding This research was funded by WHO.

Disclaimer At the time of writing, LNA was a consultant to WHO. The authors alone are responsible for the views expressed in this article, and they do not necessarily represent the decisions, policy or views of WHO.

Competing interests None declared.

Provenance and peer review Not commissioned; externally peer reviewed.

Data sharing statement Original search results, the search strategies used for each database, and the coding spreadsheet for included papers are available from LNA via email.

Open Access This is an Open Access article distributed in accordance with the Creative Commons Attribution Non Commercial (CC BY-NC 4.0) license, which permits others to distribute, remix, adapt, build upon this work non-commercially, and license their derivative works on different terms, provided the original work is properly cited and the use is non-commercial. See: http://creativecommons.org/ licenses/by-nc/4.0/

(c) Article author(s) (or their employer(s) unless otherwise stated in the text of the article) 2017. All rights reserved. No commercial use is permitted unless otherwise expressly granted.

\section{REFERENCES}

1. World Health Organization. 2014. Global Status Report on NCDs 3013-2020. Geneva WHO.

2. Institute for Health Metrics and Evaluation (IHME). GBD Compare. Seattle, WA: IHME, University of Washington, 2015. http://vizhub. healthdata.org/gbd-compare. (accessed 18 May 2016).

3. Allen L, Cobiac L, Townsend N. Quantifying the global distribution of premature mortality from non-communicable diseases. J Public Health. In Press. 2017:1-6.

4. Horton R. Offline: Chronic diseases-the social justice issue of our time. The Lancet 2015;386:2378.

5. United Nations General Assembly. A/RES/66/2. Political Declaration of the High-level Meeting of the General Assembly on the Prevention and Control of Noncommunicable Diseases, 2011.

6. Jaspers L, Colpani V, Chaker L, et al. The global impact of noncommunicable diseases on households and impoverishment: a systematic review. Eur J Epidemiol 2015;30:163-88.

7. Muka T, Imo D, Jaspers L, et al. The global impact of noncommunicable diseases on healthcare spending and national income: a systematic review. Eur J Epidemiol 2015;30:251-77.

8. Chaker L, Falla A, van der Lee SJ, et al. The global impact of non-communicable diseases on macro-economic productivity: a systematic review. Eur J Epidemiol 2015;30:357-95. 
9. Bloom DE, Cafiero E, Jané-Llopis E, et al. The global economic burden of noncommunicable diseases. Program on the Global Demography of Aging, 2012.

10. Daniels ME, Donilon TE, Bollyky TJ. The emerging global health crisis: Noncommunicable diseases in low- and middle-income countries. SSRN Electronic Journal 2014;5

11. Mahal A, Karan A, Engelau M. The economic implications of non communicable disease for India. Washington: World Bank, 2010.

12. World Health organization. From burden to "best buys": reducing the economic impact of NCDs in low- and middle income countries. Geneva: WHO and World Economic Forum, 2011.

13. Hosseinpoor AR, Bergen N, Mendis S, et al. Socioeconomic inequality in the prevalence of noncommunicable diseases in lowand middle-income countries: results from the World Health Survey. BMC Public Health 2012;12:474.

14. Hosseinpoor AR, Bergen N, Kunst A, et al. Socioeconomic inequalities in risk factors for non communicable diseases in lowincome and middle-income countries: results from the World Health Survey. BMC Public Health 2012;12:1.

15. Sommer I, Griebler U, Mahlknecht P, et al. Socioeconomic inequalities in non-communicable diseases and their risk factors: an overview of systematic reviews. BMC Public Health 2015;15:1.

16. World Health Organization. Global Health Risks: mortality and burden of disease attributable to selected major risks. Geneva: World Health Organisation, 2009.

17. Mackenbach JP, Stirbu I, Roskam AJ, et al. Socioeconomic inequalities in health in 22 European countries. $N$ Engl $\mathrm{J} \mathrm{Med}$ 2008;358:2468-81.

18. Dalstra JA, Kunst AE, Borrell C, et al. Socioeconomic differences in the prevalence of common chronic diseases: an overview of eight European countries. Int J Epidemiol 2005;34:316-26.

19. Theme-Filha MM, Szwarcwald CL, Souza-Júnior PRBde. Sociodemographic characteristics, treatment coverage, and self-rated health of individuals who reported six chronic diseases in Brazil, 2003. Cad Saude Publica 2005;21:S43-53.

20. Kaplan GA, Keil JE. Socioeconomic factors and cardiovascular disease: a review of the literature. Circulation 1993;88:1973-98.

21. Leeder S, Raymond S, Greenberg H, et al. A race against time: the challenge of cardiovascular disease in developing economies. New
York: The Center for Global Health and Economic Development, 2004.

22. Allen L, Williams J, Townsend N, et al. Socioeconomic status and non-communicable disease behavioural risk factors in low-income and lower-middle-income countries: a systematic review. Lancet Glob Health 2017:5:e277-e289.

23. United Nations General Assembly. Addis Abba Action Agenda, 2015.

24. World Health Organization. Global action plan for the prevention and control of noncommunicable diseases 2013-2020. Geneva: WHO, 2014.

25. Jones AC, Geneau R. Assessing research activity on priority interventions for non-communicable disease prevention in low- and middle-income countries: a bibliometric analysis. Glob Health Action 2012;5:18847.

26. World Bank. Country and lending groups: analytic classifications. 2015 http://data.worldbank.org/about/country-and-lending-groups (accessed 15 Jul 2016).

27. Lucas A, Mogedal S, Walt G, et al. Cooperation for health development: the World Health Organization's support to programmes at country level. Synthesis report. London: London School of Hygiene and Tropical Medicine, 1997.

28. Akinremi TO. Research collaboration with low resource countries: overcoming the challenges. Infect Agent Cancer 2011;6:S3.

29. Dakik HA. The challenges of cardiovascular research in developing countries. J Am Coll Cardiol 2008;52:83-4.

30. Dakik HA, Kaidbey H, Sabra R. Research productivity of the medical faculty at the American University of Beirut. Postgrad Med $J$ 2006;82:462-4.

31. Sitthi-Amorn $C$, Somrongthong R. Strengthening health research capacity in developing countries: a critical element for achieving health equity. BMJ 2000;321:813-7.

32. Mendis S, Alwan A. Prioritized research agenda for prevention and control of noncommunicable diseases. Geneva: World Health Organization, 2011.

33. World Health Organization. Global action plan for the prevention and control of noncommunicable diseases 2013-2020: WHO Geneva, 2013. 